\title{
An improved cutting force model for micro milling considering machining dynamics
}

\author{
Wanqun Chen $^{1,2} \cdot$ Xiangyu Teng ${ }^{1} \cdot$ Dehong Huo ${ }^{1}$ Q Quanlong Wang ${ }^{2}$
}

Received: 15 March 2017 / Accepted: 22 June 2017 / Published online: 12 July 2017

(C) The Author(s) 2017. This article is an open access publication

\begin{abstract}
Micro milling, as a versatile micro machining process, is kinematically similar to conventional milling; howev$\mathrm{er}$, it is significantly different from conventional milling with respect to chip formation mechanisms and uncut chip thickness modelling, due to the comparable size of the edge radius to the chip thickness, and the small per-tooth feeding. Considering tool runout and dynamic displacement between the tool and the workpiece, the contour of the workpiece left by previous tool paths is typically in a wavy form, and the wavy surface provides a feedback mechanism to cutting force generation because the instantaneous uncut chip thickness changes with both the vibration during the current tool path and the surface left by the previous tool paths. In this study, a more accurate uncut chip thickness model was established including the precise trochoidal trajectory of the cutting edge, tool runout and dynamic modulation caused by the machine tool system vibration. The dynamic regenerative effect is taken into account by considering the influence of all the previous cutting trajectories using numerical iteration; thus, the multiple time delays (MTD) are considered in this model. It is found that transient separation of the tool-workpiece occurring at a low feed per tooth, caused by MTD and the existing cutting force models, is no longer applicable when transient tool-workpiece separation occurs. Based on the proposed uncut chip thickness model, an improved cutting force model of micro milling is developed by full consideration of the
\end{abstract}

Dehong Huo

dehong.huo@newcastle.ac.uk

1 School of Mechanical and Systems Engineering, Newcastle University, Newcastle upon Tyne NE1 7RU, UK

2 Center for Precision Engineering, Harbin Institute of Technology, Harbin 150001, People's Republic of China ploughing effect and elastic recovery of the workpiece material. The proposed cutting force model is verified by micro end milling experiments, and the results show that the proposed model is capable of producing more accurate cutting force prediction than other existing models, particularly at small feed per tooth.

Keywords Micro milling $\cdot$ Cutting force model $\cdot$ Uncut chip thickness $\cdot$ Tool runout $\cdot$ Machine tool dynamics

\section{Introduction}

The increasing demand on micro and miniature parts, components and systems has led to the development of micro manufacturing technology. It is well-recognized that micro manufacturing has been a key enabling technology in industries producing useful micro components and products [1]. Micro milling is recognized as a versatile process and has found its application in processing various materials due to its wide material machining ability, high processing efficiency, low cost and low environmental requirements [2-6].

Due to their small diameter, typically between 0.1 and $1 \mathrm{~mm}$, micro cutters have much lower stiffness but experience much higher stress variation on the tiny shaft compared with conventional tools; hence, micro cutters are prone to tool wear and breakage. A well-developed cutting force model with precise force prediction can assist operators in choosing the optimal cutting parameters; furthermore, the predicted toolworkpiece dynamic displacement can be used for tool path adjustment in order to increase the accuracy of machined parts and reduce tool breakage [7-9]. Therefore, developing an accurate cutting force model becomes imperative for micro milling process. 
As aforementioned, micro milling requires micro tools and hence high rotational speeds to achieve even modest machining rates. The rotational speeds in micro milling are always higher than $5000 \mathrm{rpm}$ and even up to $300,000 \mathrm{rpm}$. Therefore, tool manufacturing errors and tool alignment errors become relatively large compared to the associated chip load. The dynamic tool runout can be considered as the total figure for these errors. Different from conventional milling, the tool runout to tool diameter ratio cannot be neglected in micro milling; thus, it has significant influence on the machining process [10]. The tool runout makes the cutting force variation increase significantly, resulting in severe tool wear and even breakage. Therefore, the tool runout must be carefully considered in micro milling force modelling. In addition, the machine tool system vibration will change the cutter edge location and leave a wavy surface. The wavy surface in turn provides a feedback mechanism to cutting forces because the instantaneous uncut chip thickness depends on both the vibration during the current tool path and the surface left by the previous tool paths, which form multiple time delays (MTD).

Numerous researches have been carried out on micro milling force modelling. An analytical expression for the chip thickness of micro end milling considering the tool runout was first studied by Bao and Tansel [11]. Li et al. [12] proposed an instantaneous uncut chip thickness algorithm for micro milling operation by considering the combination of an exact trochoidal trajectory of the tool tip and the tool runout. Different from conventional cutting, in micro milling, the cutting tool edge radius has an important influence on the cutting mechanism; therefore, Kang et al. [13] established a cutting force model considering the edge radius of micro cutting tools, in which the ploughing effect at the tool edge and the sliding on the flank face were modelled. Gye et al. [14] obtained the deformation of the micro tool based on the cutting force predicted; however, the influence of the deformation of the micro tool on the cutting force was not studied. Wang et al. [15] proposed a micro milling cutting force model considering the minimum chip thickness effect, cutter deflection and spindle runout. Based on the proposed cutting force model, a method to determine the optimal micro milling parameters was developed. Lee et al. [16] proposed a mechanistic cutting force model considering the minimum chip thickness effect. Another mechanistic model for the micro end milling process was developed by Vogler et al. [17] to address the high frequencies in the cutting force signal caused by the multiple phases in the material. Jin and Altintas [18] presented a slip-line field model using a finite element model, in which the stress variation in the material deformation region due to the tool edge radius effect was considered. Kumanchik et al. [19] developed an analytical formula for the uncut chip thickness by considering the trochoidal tool path, runout and uneven tooth spacing. Schmitz et al. [20] investigated the effect of milling cutter teeth runout on surface topography, surface location error and stability in end milling. Relationships between runout, surface finish, stability and surface location error were obtained via simulation. Li et al. [21] proposed a generic instantaneous uncut chip thickness model, in which all passing teeth cutting trajectories in 1 cycle were considered. Zhang et al. [22] proposed a cutting force model for micro milling which includes an algorithm for the calculation of the variable entry and exit angles caused by tool runout and tool deflection.

In the previous studies, the uncut chip thickness was always obtained from the current and the immediately preceding passing tool path, forming a continuous cutting thickness, and the influence of the workpiece material removed by other previous tool paths was neglected. Actually, the uncut chip thickness is determined by the maximum contour formed by all the previous cutting trajectories and the current cutting trajectory. When fully considering the combination of the exact trochoidal trajectory of the tool tip, tool runout and machining system dynamics, the milling process becomes highly intermittent, especially when the magnitude of the tool runout and dynamic vibration is comparable to the feed rate. Cutting edges may not be in contact with the workpiece for some time during one tool passing period, i.e. transient tool-workpiece separation. The chip generated by one cutting tooth is intermittent even in one tool edge passing period. Figure 1 shows the schematic of micro milling process considering the abovementioned factors. The wavy surface left behind by the previous tool edge trajectories is being removed by the current trajectory. It can be noted that the maximum contour is affected by the several previous tool edge trajectories, rather than merely the immediately preceding cutting trajectory. As shown in Fig. 1, transient tool-workpiece separation occurs in some areas and the overlap between the current cutting trajectory and the several previous trajectories forms the instantaneous uncut chip thickness. However, in previous studies, only the immediately preceding tool edge trajectory is considered, and the transient tool-workpiece separation is ignored by assuming that each tooth is in contact with the workpiece over a constant time interval and that the workpiece is always engaged by the cutter. In addition, the tool trajectory is recognized as trochoidal trajectory; thus, the feed rate effect on the time delay is also ignored.

In this paper, a comprehensive uncut chip thickness model considering both the tool runout and the machining system dynamics is proposed by using the cutting edge trajectory iteration. The actual uncut chip thickness formed by the resultant periodicity of the tool can be obtained at specified cutting angles. The uncut chip thickness becomes much complex when considering the tool runout, the dynamic performance of the cutting system and the transient separation of toolworkpiece discussed above. It may not be possible to derive an analytical solution of the instantaneous uncut chip thickness. Thus, a numerical iterative algorithm was developed to 
Fig. 1 Schematic of micro milling process

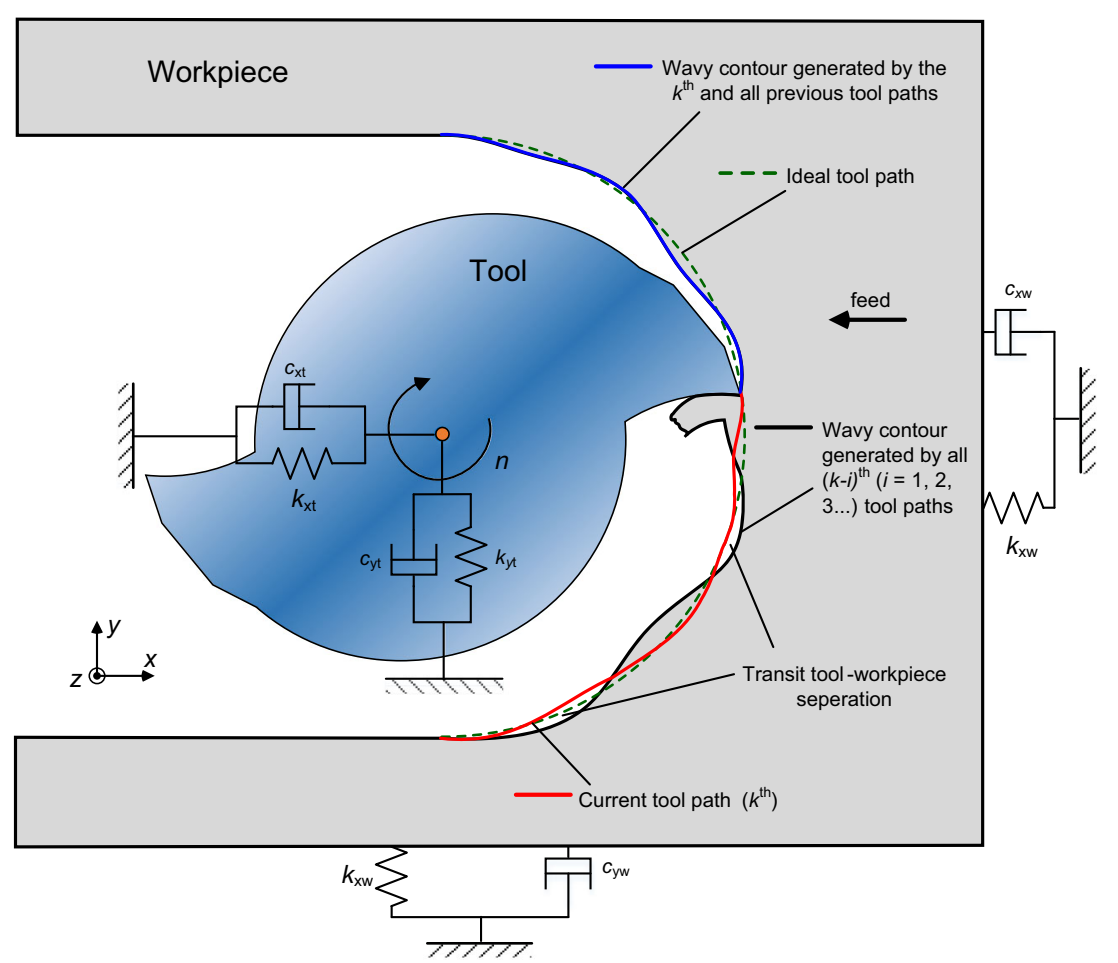

calculate the instantaneous uncut chip thickness, in which all of the previous cutting trajectories involved in the formation of the instantaneous chip thickness are considered. Therefore, this model is expected to be more accurate compared to the existing models, especially when the feed rate is comparable to tool runout and dynamic vibration magnitude. Based on the uncut chip thickness model, an improved cutting force model is established considering the effects of ploughing and elastic recovery of the workpiece material. Finally, micro milling experiments were conducted to validate the model.

\section{The influence of the machine tool system dynamic performance on the cutting force}

As shown in Fig. 2, a typical cutting force model includes various input parameters, namely, cutting parameters, tool geometry parameters and machine system parameters. Most of the existing cutting force models calculate the instantaneous uncut chip thickness entirely based on these input parameters and given entrance and exit angles. Cutting coefficients are determined by either mechanistic or numerical methods. Then, cutting forces can be determined in this non-iterative approach. However, the real situation of cutting force generation in micro milling is an iterative process. The cutting force generation can be described as a feedback system: The micro cutter removes a certain volume of the workpiece material and generates cutting force, while the cutting force acts on the machining system (both the cutter and the workpiece), which causes the deformation of the cutter and workpiece and forms a feedback to the instantaneous uncut chip thickness. Considering the low stiffness of the micro machining system, the deformation between the tool and workpiece caused by the cutting force generated in the machining process is not negligible.

In order to establish the dynamic model of the micro machine tool system, the structural loop of the machine tool is divided into a cutter-machine loop and a workpiece-machine loop, and each loop can be simplified as two single-degree-offreedom systems in $x$ (feed direction) and $y$ (cross-feed direction), respectively, as shown in Figs. 1 and 3. The equations of motion are as follows:

$\left\{\begin{array}{l}m_{x t} \ddot{x}_{t}(t)+c_{x t} \dot{x}_{t}(t)+k_{x t} x_{t}(t)=F_{x}(t) \\ m_{y t} \ddot{y}_{t}(t)+c_{y t} \dot{y}_{t}(t)+k_{y t} y_{t}(t)=F_{y}(t) \\ m_{x w} \ddot{x}_{w}(t)+c_{x w} \dot{x}_{w}(t)+k_{w t} x_{w}(t)=-F_{x}(t) \\ m_{y w} \ddot{y}_{w}(t)+c_{y w} \dot{y}_{w}(t)+k_{y w} y_{w}(t)=-F_{y}(t)\end{array}\right.$

where $m_{x t}, c_{x t}$ and $k_{x t}$, and $m_{x w}, c_{x w}$ and $k_{x w}$ are the mass, damping and stiffness of the cutter-machine loop and the workpiece-machine loop in the $x$ direction, respectively; $m_{y t}$, $c_{y t}$ and $k_{y t}$, and $m_{y w}, c_{y w}$ and $k_{y w}$ are the mass, damping and stiffness of the cutter-machine loop and the workpiecemachine loop in the $y$ direction, respectively, and $F_{x}(t)$ and $F_{y}(t)$ are the instantaneous cutting force in the $x$ and $y$ directions, respectively. $x_{t}, \dot{x}_{t}$ and $\ddot{x}_{t}$ and $y_{\mathrm{t}}, \dot{y}_{t}$ and $\ddot{y}_{t}$ are the positions, velocities and accelerations of the cutter in the $x$ and $y$ directions; $x_{w}, \dot{x}_{w}$ and $\ddot{x}_{w}$ and $y_{w}, \dot{y}_{w}$ and $\ddot{y}_{w}$ are the positions, velocities and accelerations of the workpiece in the $x$ and $y$ directions. 
Fig. 2 Schematic of cutting force generation

\begin{tabular}{|l|}
\hline \multicolumn{1}{|c|}{ Input parameters } \\
\hline Cutting parameters \\
Feed per tooth \\
Cutting depth \\
Spindle speed
\end{tabular}

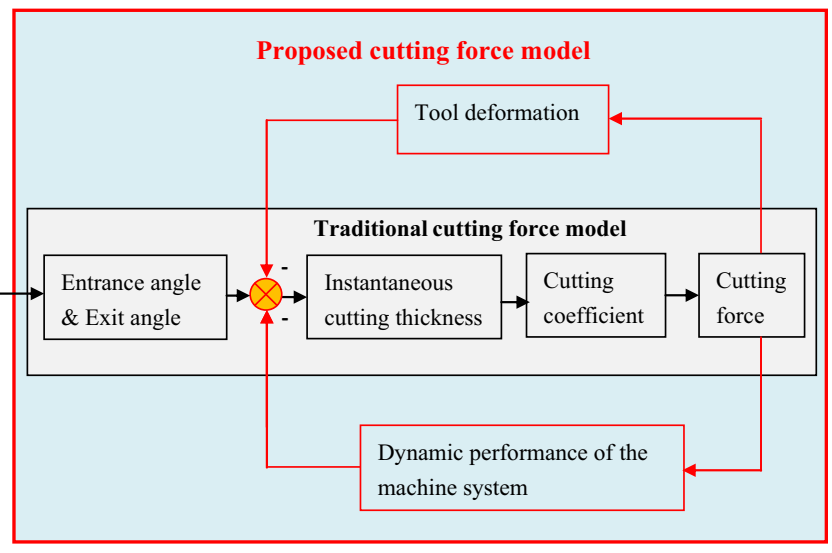

Rewriting Eq. (1), the expressions for the accelerations in the $x$ and $y$ directions in the current time step can be given as

$$
\left\{\begin{array}{l}
\ddot{x}_{t}(t)=\frac{F_{x}(t)-c_{x t} \dot{x}_{t}(t)-k_{x t} x_{t}(t)}{m_{x t}} \\
\ddot{y}_{t}(t)=\frac{F_{y}(t)-c_{y t} \dot{y}_{t}(t)-k_{y t} y_{t}(t)}{m_{y t}} \\
\ddot{x}_{w}(t)=\frac{-F_{x}(t)-c_{x w} \dot{x}_{w}(t)-k_{w t} x_{w}(t)}{m_{x w}} \\
\ddot{y}_{w}(t)=\frac{-F_{y}(t)-c_{y w} \dot{y}_{w}(t)-k_{y w} y_{w}(t)}{m_{y w}}
\end{array}\right.
$$

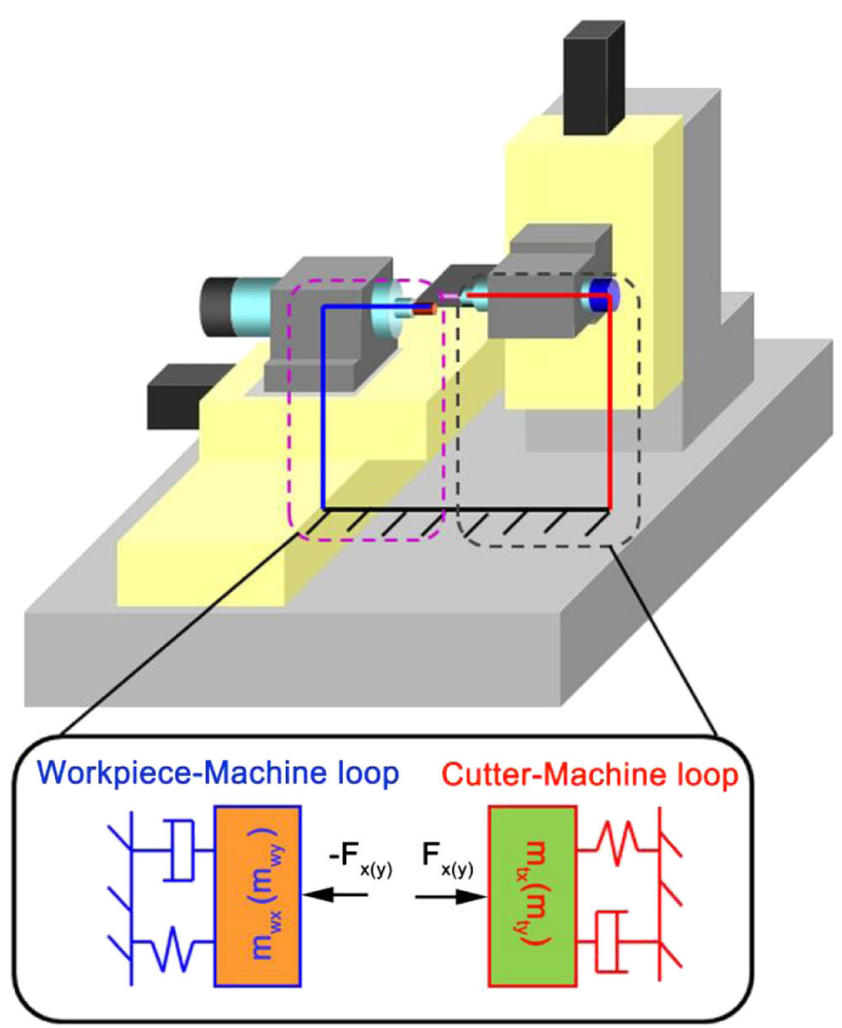

Fig. 3 Schematic diagram of the machine tool loop where the velocities, $\dot{x}$ and $\dot{y}$, and positions, $x$ and $y$, from the previous time step are used to calculate the acceleration at the current time step. The new velocities and positions at the current time step are then determined by numerical integration:

$\left\{\begin{array}{l}\dot{x}_{t}(t)=\dot{x}_{t}(t)+\ddot{x}_{t}(t) d t \\ \dot{y}_{t}(t)=\dot{y}_{t}(t)+\ddot{y}_{t}(t) d t \\ \dot{x}_{w}(t)=\dot{x}_{w}(t)+\ddot{x}_{w}(t) d t \\ \dot{y}_{w}(t)=\dot{y}_{w}(t)+\ddot{y}_{w}(t) d t\end{array}\right.$
$\left\{\begin{array}{l}x_{t}(t)=x_{t}(t)+\dot{x}_{t}(t) d t \\ y_{t}(t)=y_{t}(t)+\dot{y}_{t}(t) d t \\ x_{w}(t)=x_{w}(t)+\dot{x}_{w}(t) d t \\ y_{w}(t)=y_{w}(t)+\dot{y}_{w}(t) d t\end{array}\right.$

where the velocities and the displacement on the right-hand side of the equation in Eqs. (3) and (4) are retained from the previous time step. The new velocities are then used to determine the new displacements in Eq. (4). $d t$ is the time interval set by the program.

The relative dynamic displacement between the tool and workpiece in the $x$ and $y$ directions can be given as

$$
\left\{\begin{array}{l}
x_{t w}(t)=x_{t}(t)-x_{w}(t) \\
y_{t w}(t)=y_{t}(t)-y_{w}(t)
\end{array}\right.
$$

\section{Calculation of uncut chip thickness}

In micro end milling, a comprehensive methodology to calculate the uncut chip thickness is required to include the influences of both the process parameters and the dynamic vibration between the tool and workpiece during the machining process.

The tool tip trajectories of the end milling operations are illustrated in Fig. 4a where the red and blue lines represent the tool tip trajectories of the $\left(K^{-1}\right)^{\text {th }}$ and $K^{\text {th }}$ cutting edges, 

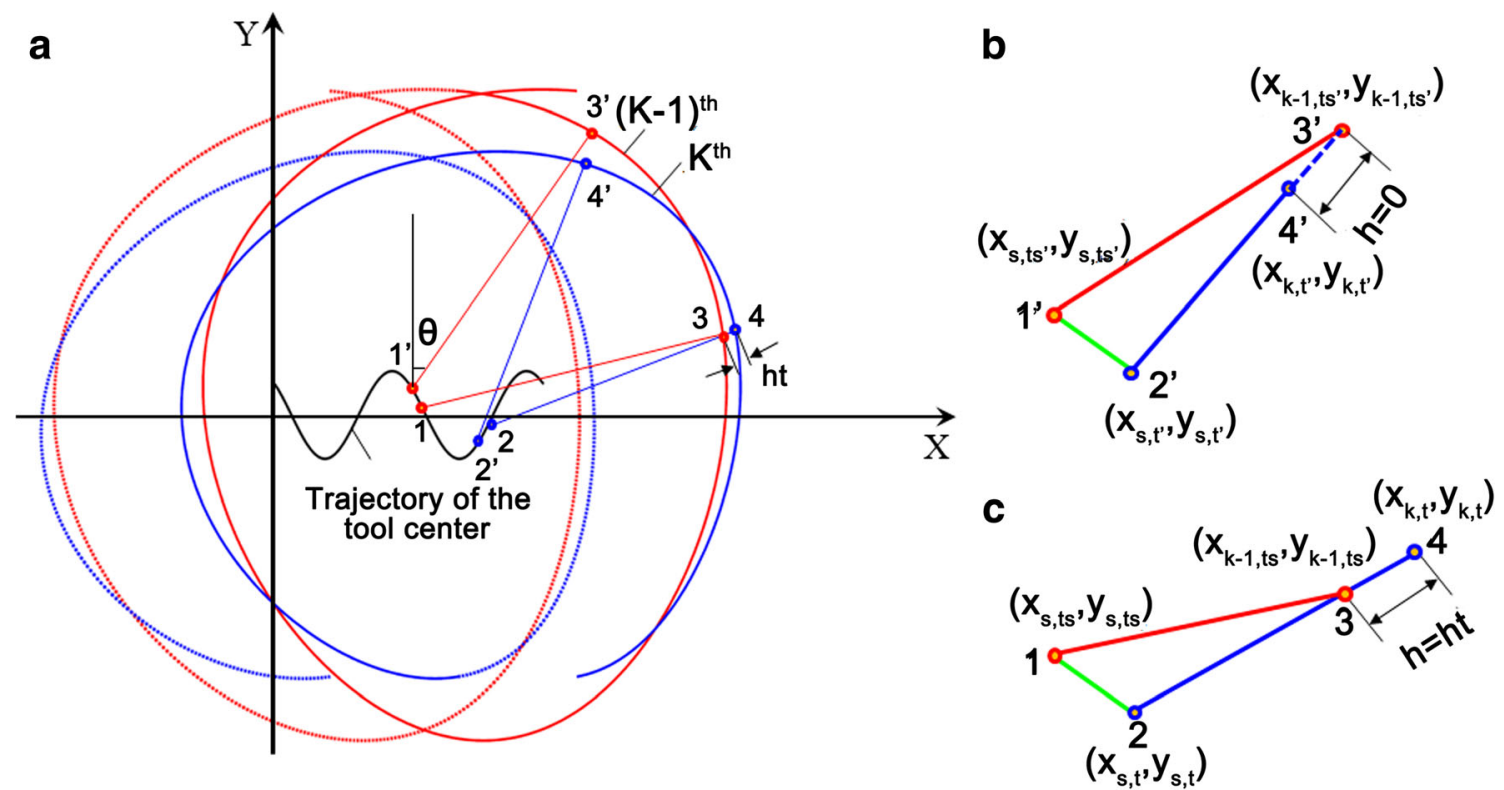

Fig. 4 a Schematic diagram of tool edge trajectories in micro milling. b A case showing transient separation of the workpiece and cutter. $\mathbf{c}$ A case showing non-zero instantaneous uncut chip thickness

respectively, where $K$ is the number of tool flute. By combining the effect of the tool runout and the dynamic vibration, the trajectory of the tool center, $\left(x_{s, t}, y_{s, t}\right)$, can be given as

$\left\{\begin{array}{l}x_{s, t}=f t+r_{0} \sin (\omega t+\gamma)+x_{t w}(t) \\ y_{s, t}=r_{0} \cos (\omega t+\gamma)+y_{t w}(t)\end{array}\right.$

where $f$ is the feed rate of the workpiece $(\mathrm{mm} / \mathrm{s}), r_{0}$ is the magnitude of the tool runout $(\mathrm{mm}), \gamma$ is the runout angle $(\mathrm{rad})$ and $\omega$ is the spindle rotational speed $(\mathrm{rad} / \mathrm{s})$.

Hence, the trajectory of the $K^{\text {th }}$ tool tip can be given as

$$
\left\{\begin{array}{l}
x_{k}(t)=f t+r \sin \left(\omega t-\frac{2 \pi k}{K}\right)+r_{0} \sin (\omega t+\gamma)+x_{t w}(t) \\
y_{k}(t)=r \cos \left(\omega t-\frac{2 \pi k}{K}\right)+r_{0} \cos (\omega t+\gamma)+y_{t w}(t)
\end{array}\right.
$$

where $r$ is the tool radius (mm), and $k=0,1,2, \ldots, \mathrm{K}-1\left(x_{k, t}\right.$, $\left.y_{k, t}\right)$ denotes the coordinate of the $K^{\text {th }}$ tool tip at time $t$ with the position angle $\theta=\omega t$.

Equation (6) can be rewritten as

$$
\begin{aligned}
y_{k}(t)= & \frac{x_{k}(t)-f t-r_{0} \sin (\omega t+\gamma)-x_{t w}(t)}{\tan \left(\omega t-\frac{2 \pi k}{K}\right)}+r_{0} \cos (\omega t+\gamma) \\
& +y_{t w}(t)
\end{aligned}
$$

The line connecting $\left(x_{k, t}, y_{k, t}\right)$ and its corresponding tool center $\left(x_{s, t}, y_{s, t}\right)$ is denoted as line $l$. The $(K-1)^{\text {th }}$ tool tip trajectory can be obtained from Eq. (3) by replacing $K$ with $(K-i)$ and $t$ with $t_{s}$. The intersection point of the line $l$ and the
$(K-\mathrm{i})^{\text {th }}$ tool tip trajectory is the position of the $(K-i)^{\text {th }}$ tool tip at time $t_{s}$.

The equation of line $l$ can be expressed by

$\frac{y_{k}-y_{k-i}}{x_{k}-x_{k-i}}=\frac{y_{k-i}-y}{x_{k-i}-x}$

Equation (8) also can be rewritten as

$y=\cot \left(\omega t-\frac{2 \pi k}{K}\right)\left(x-x_{s, t}\right)+y_{s, t}$

Combined with Eq. (5), Eq. (9) can be written as

$$
\begin{aligned}
y= & \cot \left(\omega t-\frac{2 \pi k}{K}\right)\left(x-f t-r_{0} \sin (\omega t+\gamma)-x_{t w}(t)\right) \\
& +r_{0} \cos (\omega t+\gamma)+y_{t w}(t)
\end{aligned}
$$

Using the condition that the point $\left(x_{k-i, t s}, y_{k-i, t s}\right)$ is on the line $l$, thus, its coordinates can be solved by Eqs. (7) and (10).

In order to find the coordinate of the point on the outline corresponding with the coordinate $\left(x_{k, t}, y_{k, t}\right)$ generated, the $K^{\text {th }}$ tool tip is denoted as $\left(x_{k-i, t s}, y_{k-i, t s}\right)$. Then, the outline generated by the previous $(K-\mathrm{i})$ tool tips can be written as

$$
\left(x_{k^{\prime}}, y_{k^{\prime}}\right)=\max \left(x_{k-i, t s}^{2}+y_{k-i, t s}^{2}\right)
$$

From Fig. 4b, it can be noted that when $\frac{x_{k, t}^{2}+y_{k, t}^{2}}{x_{k^{\prime}}^{2}+y_{k^{\prime}}^{2}} \leq 1$, the cutting edge of the $k^{\text {th }}$ flute is the interior of the contour of the trajectory of the $(k-i)^{\text {th }}$ flute, which means that no material is removed by the $k^{\text {th }}$ flute. Thus, the instantaneous chip 


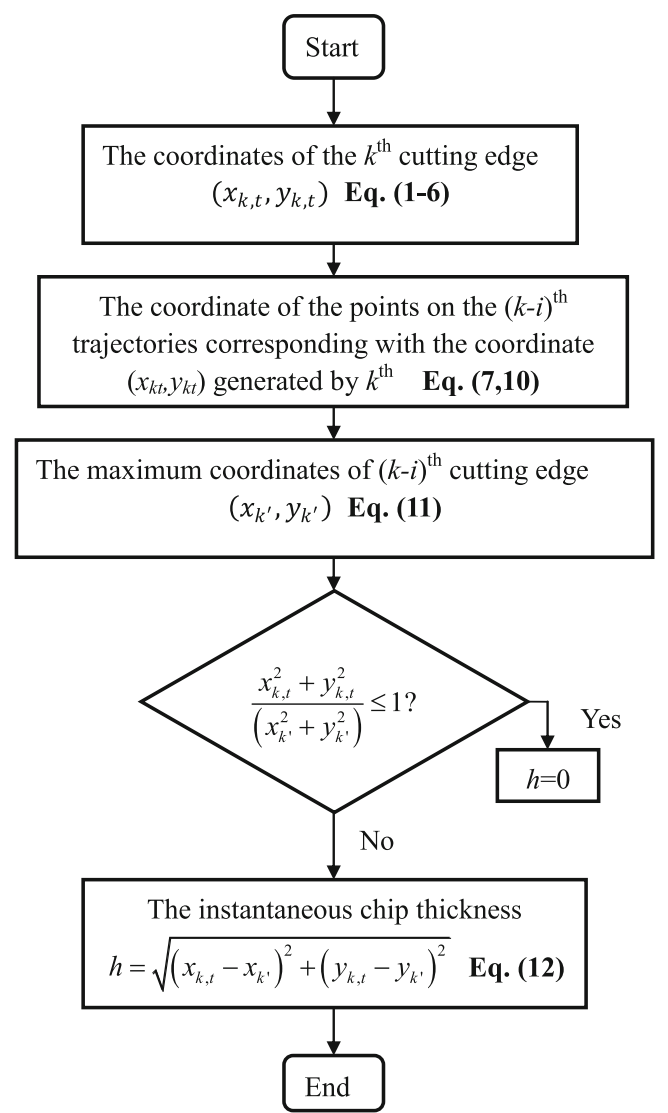

Fig. 5 Flow chart for determination of the nominal uncut chip thickness

thickness is 0 . When $\frac{x_{k, t}^{2}+y_{k, t}^{2}}{x_{k^{\prime}}^{2}+y_{k^{\prime}}^{2}}>1$, the workpiece material is removed by the $k^{\text {th }}$ flute, as shown in Fig. 4c.
Thus, the instantaneous uncut chip thickness can be calculated as

$h(t, k)= \begin{cases}0 & , \frac{x_{k, t}^{2}+y_{k, t}^{2}}{x_{k^{\prime}}^{2}+y_{k^{\prime}}^{2}} \leq 1 \\ \sqrt{\left(x_{k, t}-x_{k^{\prime}}\right)^{2}+\left(y_{k, t}-y_{k^{\prime}}\right)^{2}} & , \frac{x_{k, t}^{2}+y_{k, t}^{2}}{x_{k^{\prime}}^{2}+y_{k^{\prime}}^{2}}>1\end{cases}$

Figure 5 shows a flow chart for determination of uncut chip thickness $h(t, k)$ with respect to a specific time $t$ and tool flute, $k$.

Cutting force model In the micro end milling process, the cutting edge radius is comparable to the feed per tooth. Typically, three types of material removal mechanisms take place in one tool edge engagement cycle [23], as shown in Fig. 6.

Type 1: Elastic deformation When the uncut chip thickness is smaller than a certain critical value $h_{c}$, only elastic deformation occurs in the workpiece. The deformed material fully recovers to its original position, and as a result, no chip is formed.

Type 2: Elastic-plastic deformation As the uncut chip thickness increases close to $h_{c e}$, the elastic-plastic deformation occurs in the workpiece. There is a constant percentage of the material undergoing plastic deformation, and the rest of the material has elastic recovery as the tool passes.

Type 3: Plastic deformation As the uncut chip thickness increases to minimum chip thickness, denoted as $h_{c}$, the
Fig. 6 Three types of material removal mechanisms in micro milling

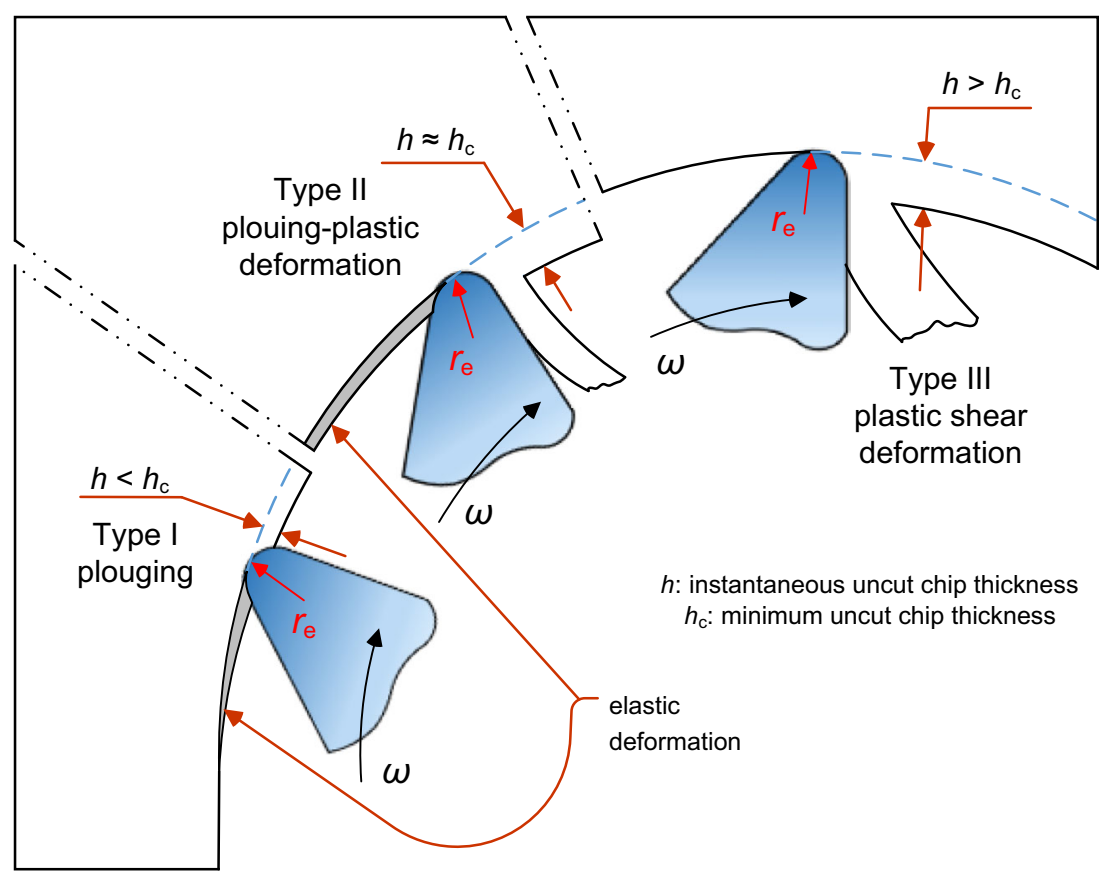




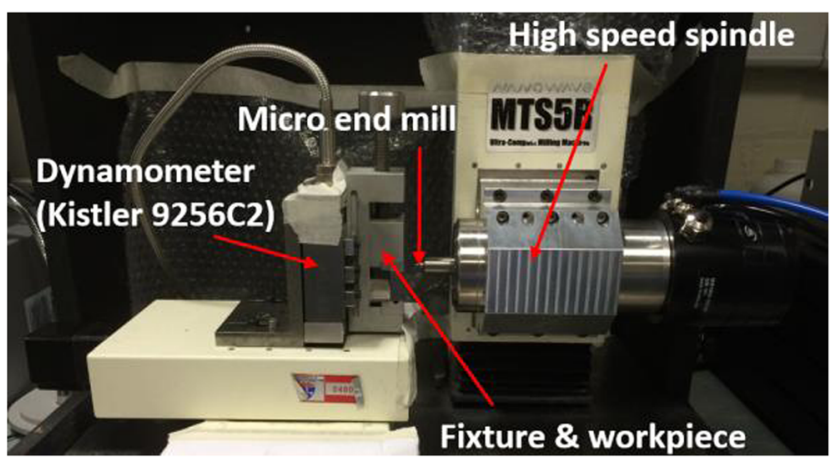

Fig. 7 Machine tool system

workpiece material is removed by the cutter as a chip, and the elastic recovery becomes very small and negligible.

Thus, in micro end milling, all of the three types of material removal mechanisms may occur in a single path of each flute. The region of type 2 is very small; thus, this region can be ignored in the cutting force modelling.

In milling operations, tangential $\left(d F_{t}\right)$, radial $\left(d F_{r}\right)$ and axial $\left(d F_{a}\right)$ forces, acting on a differential flute element with height $d z$, can be modelled as [22]

$$
\left\{\begin{aligned}
& d F_{t}=\left\{\begin{array}{cl}
\left(K_{t c} h+K_{t e}\right) d z, & h \geq h_{c}(\text { shearing }) \\
\left(K_{t p} A_{p}+K_{t e}\right) d z, & h<h_{c}(\text { ploughing })
\end{array}\right. \\
& d F_{r}= \begin{cases}\left(K_{r c} h+K_{r e}\right) d z, & h \geq h_{c}(\text { shearing }) \\
\left(K_{r p} A_{p}+K_{r e}\right) d z, & h<h_{c}(\text { ploughing })\end{cases} \\
& d F_{a}= \begin{cases}\left(K_{a c} h+K_{a e}\right) d z, & h \geq h_{c} \text { (shearing) } \\
\left(K_{a p} A_{p}+K_{a e}\right) d z, & h<h_{c} \text { (ploughing) }\end{cases}
\end{aligned}\right.
$$

where $K_{r c}, K_{t c}$ and $K_{a c}$ are the radial, tangential and axial cutting coefficients, respectively, and $K_{r e}, K_{t e}$ and $K_{a e}$ are the radial, tangential and axial edge coefficients, respectively; $K_{r p}$, $K_{t p}$ and $K_{a p}$ are the radial, tangential and axial ploughing coefficients in the ploughing-dominant regime; $A_{p}$ is the ploughed area and $h_{c}$ is the minimum chip thickness.

Considering the small depth of cut, the cutter is approximated as straight tooth. This means the helix angle $\beta$ is set to 0 . The resulting force has to be integrated over $z$ (with a constant immersion angle $\theta$ ). Three-dimensional cutting forces, $d F_{x}, d F_{y}$ and $d F_{z}$, can be expressed as

$$
\left[\begin{array}{l}
d F_{x} \\
d F_{y} \\
d F_{z}
\end{array}\right]=\left[\begin{array}{ccc}
-\cos \theta & -\sin \theta & 0 \\
\sin \theta & -\cos \theta & 0 \\
0 & 0 & 1
\end{array}\right]\left[\begin{array}{l}
d F_{t} \\
d F_{r} \\
d F_{a}
\end{array}\right]
$$

The total cutting forces during micro milling process can be expressed as

$$
\begin{aligned}
& F_{x}=\sum d F_{x} \\
& F_{y}=\sum d F_{y} \\
& F_{z}=\sum d F_{z}
\end{aligned}
$$

Since cutting forces in the axial direction are much smaller compared to those in the planar directions, only the forces in the $x$ and $y$ directions are considered in this study.

\section{Model verification}

\subsection{Experimental setup}

The machining experiments were performed on a three-axis precision milling machine tool (NANOWAVE MTS5R). The machine tool is equipped with three precision linear stages which are driven by DC servo motors with the smallest feed of $0.1 \mu \mathrm{m}$ and a high-speed spindle which can work from 5000 to $80,000 \mathrm{rpm}$. A typical experimental setup is presented in Fig. 7. A three-component piezoelectric dynamometer (Kistler 9256C2) is mounted on the $\mathrm{X}-\mathrm{Z}$ stages to measure feed and cross-feed cutting forces. The workpiece is clamped on a fixture attached to the dynamometer.

Two-flute micro flat end mills with a diameter of $1 \mathrm{~mm}$ and cutting edge radius of $2 \mu \mathrm{m}$ were used in slot milling with $\mathrm{Al}$ 6061. In order to verify the proposed model, a wide range of feed per tooth was used in the experiments. Three sets of micro milling experiments, using 25,5 and $1 \mu \mathrm{m} /$ tooth, were performed. A spindle speed of $6000 \mathrm{rpm}$ and an axial depth of
Fig. 8 a Schematic diagram of the tool runout measurement experimental setup. b Measured results of the tool runout.
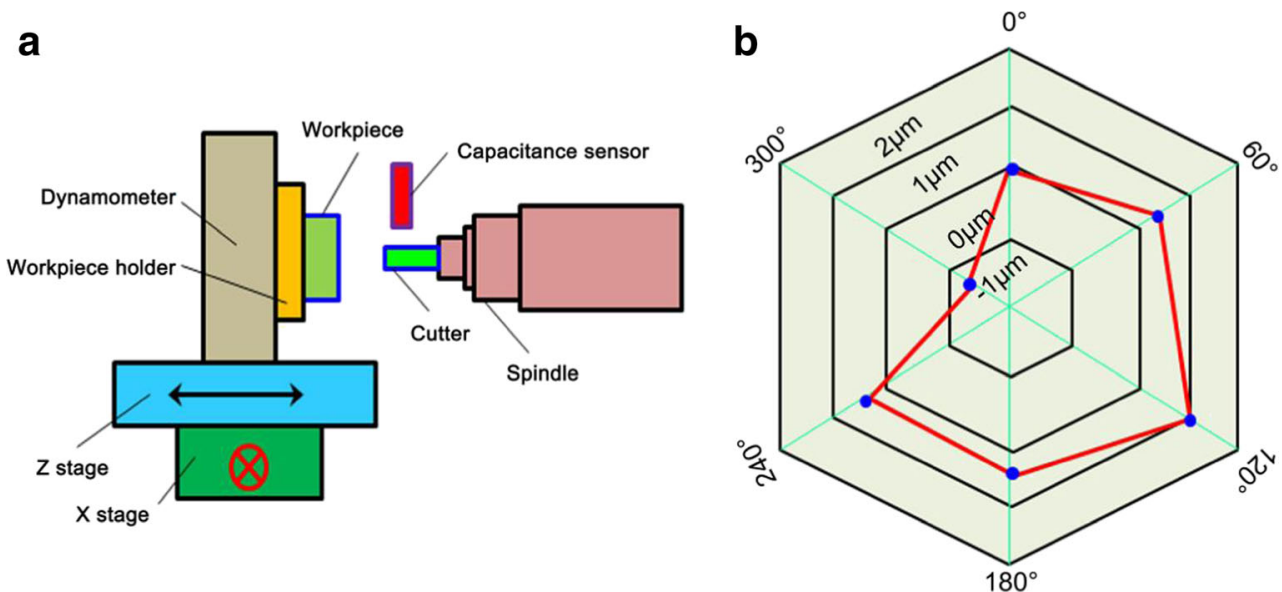
Table 1 Dynamic parameters of the machine tool system

\begin{tabular}{llcll}
\hline Direction & $\omega_{n}(\mathrm{~Hz})$ & $K(\mathrm{~N} / \mu \mathrm{m})$ & $M(\mathrm{~kg})$ & $\zeta(\%)$ \\
\hline$x_{t}$ & 500 & 1 & 0.101 & 1 \\
$y_{t}$ & 500 & 1 & 0.101 & 1.5 \\
$x_{w}$ & 420 & 33 & 4.74 & 1 \\
$y_{w}$ & 950 & 150 & 4.21 & 1.5 \\
\hline
\end{tabular}

cut of $10 \mu \mathrm{m}$ were used for all three sets of experiments. Considering the small depth of cut, the cutter is approximated as straight tooth and the $F_{z}$ can be neglected.

\subsection{Identification of tool runout and machine tool dynamic characteristics}

In this experiment, a capacitive displacement sensor (Micro-Epsilon, CS005) was used to realize the real-time runout measurements of the micro tool. Figure 8a illustrates the measurement setup for dynamic runout measurement, and the sensor probe was mounted at a distance from the shaft of the cutter, which allows the shaft in both
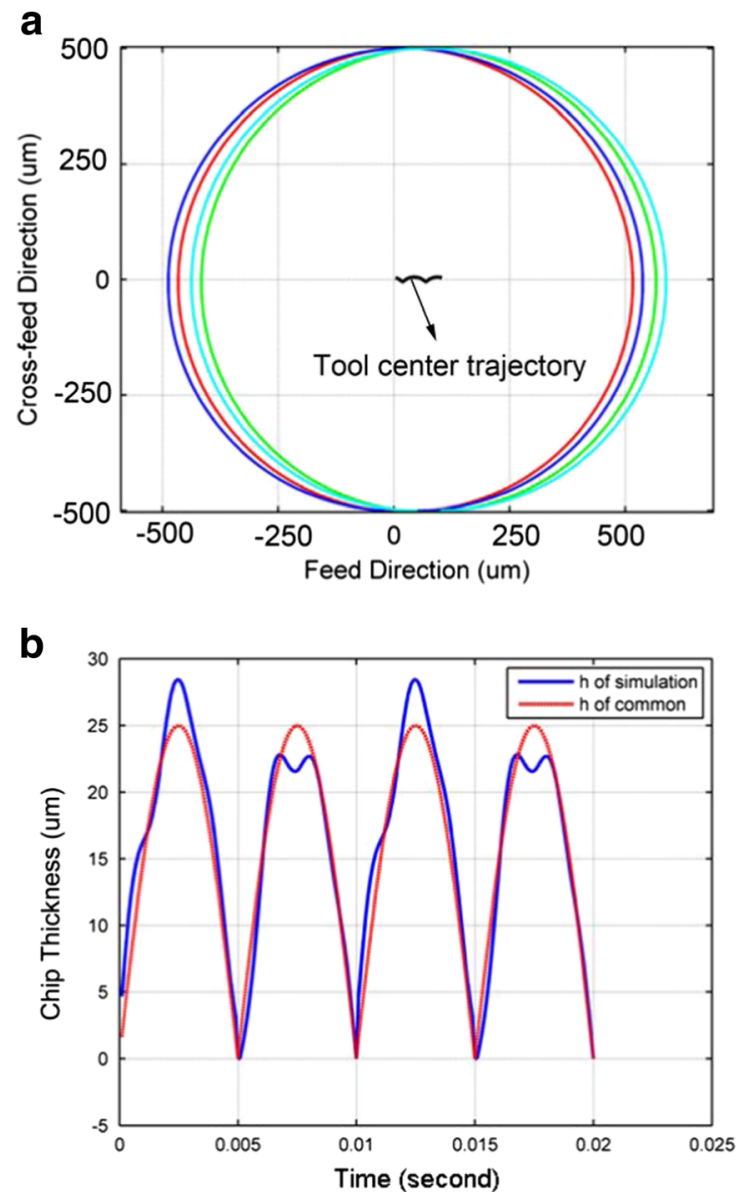

directions to stay within the functional range of probe. After that, the cutter runout is tested with a rotational speed of $6000 \mathrm{pm}$. Figure $8 \mathrm{~b}$ shows the magnitude of the tool runout and the related runout angle; the offset distance $r_{0}$ is $1 \mu \mathrm{m}$, and the runout angle is $120^{\circ}$.

The proposed model requires the dynamic parameters of the machine system, i.e. the cut-machine loop and the workpiece-machine loop, as illustrated in Fig. 3. It is difficult to obtain the dynamic parameters of the micro milling machining system due to the small diameter of the cutting tool. Therefore, the finite element simulation method is used to obtain the dynamic parameters of the machine system (shown in Table 1); the key input parameters of the machine tool components, such as bearing stiffness, material properties and damping coefficients, are extracted from relevant data sheet or determined from dynamic tests.

\subsection{Results and discussion}

In this section, the accuracy of the proposed cutting force model is evaluated, and the differences between the proposed
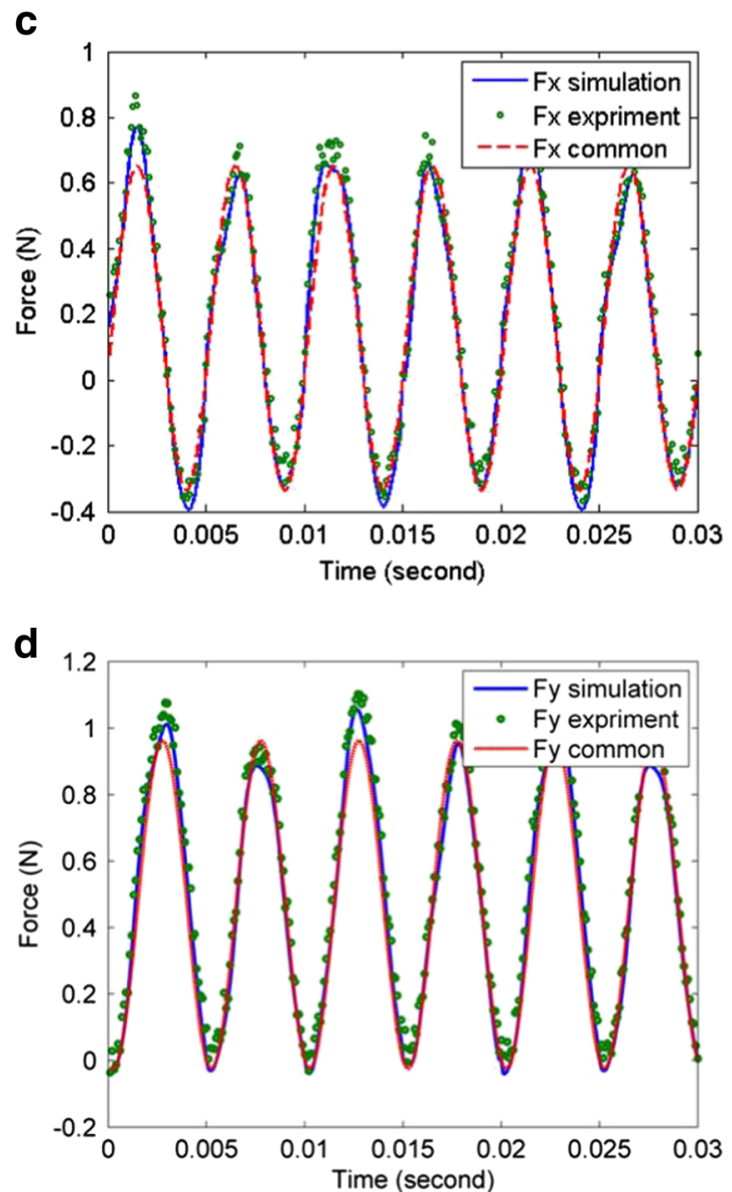

Fig. 9 One-millimetre cutter with $25-\mu \mathrm{m}$ feed per tooth. a Trajectories of the cutter. b Instantaneous cutting thickness. c Cutting force in $x$ direction. d Cutting force in $y$ direction. 
and the conventional cutting force models without considering tool runout and the dynamic effects are compared under different machining parameters.

In the conventional cutting force model without considering the size effect, the instantaneous uncut chip thickness can be obtained by

$h(\mathrm{t})=f_{t} \sin (\theta)$

In the first set of experiment, a 1-mm diameter end mill was used with $25-\mu \mathrm{m}$ feed per tooth. Figure 9a shows the trajectories of the tool cutter. It can be found that with a large feed per tooth, the tool edge trajectories are similar to those in conventional milling. Figure $9 \mathrm{~b}$ shows the uncut chip thickness predicted by both the proposed method and the conventional method without considering tool runout and vibration, with only small discrepancy observed. Cutting forces in the $x$ and $y$ directions from the proposed model, conventional model and experiments are plotted in Fig. 9c, d, respectively. It can be found that with a large feed per tooth, cutting force predictions from both models agree well with those measured in the experiments.

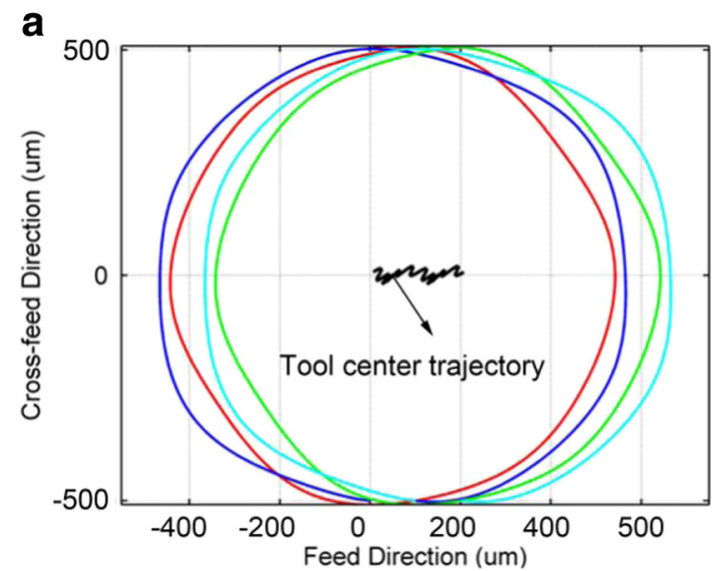

b

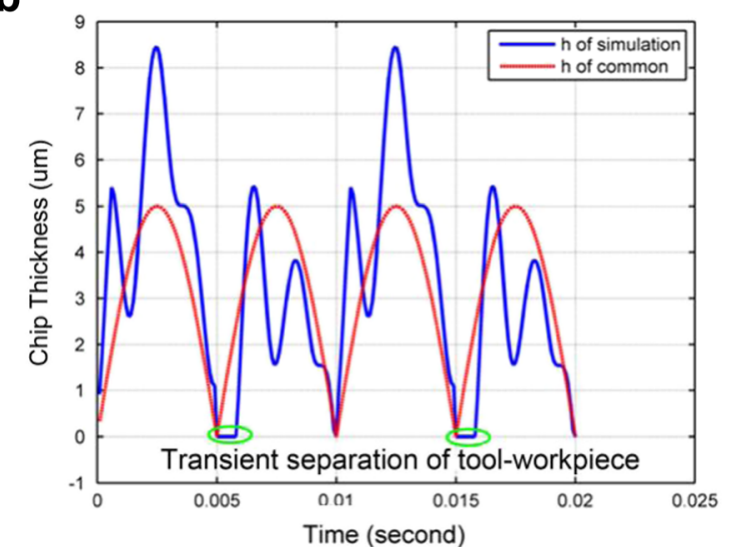

In the second set of experiments, the 1-mm diameter cutter tool with $5-\mu \mathrm{m}$ feed per tooth is used. Figure 10a shows the trajectories of the tool cutters. It can be found that the current cutting path only has intersection points with the immediately preceding cutting trajectory, which means that the chip thickness is only determined by the current and immediately preceding cutting trajectory. Figure 10b shows that the chip thickness is continuous in one tooth cutting period, and the runout effect can be noted clearly as the chip thickness in one cutting tooth is larger than the other. The fluctuation of the cutting thickness is caused by the vibration of the machine tool system. A transient separation region of tool-workpiece can be found in 1 revolution (circled in Fig. 10b). In this region, the cutting force drops to 0 , while the cutting force predicted by the conventional method is still a continuous sine wave. Due to the machining dynamics not being considered, the maximum cutting forces predicted from the conventional model $(0.14$ and $0.19 \mathrm{~N}$ in the $x$ and $y$ directions, respectively) are smaller than those measured in the experiments, while the cutting force prediction from the proposed method agrees well with the experimental results (Fig. 10c, d).
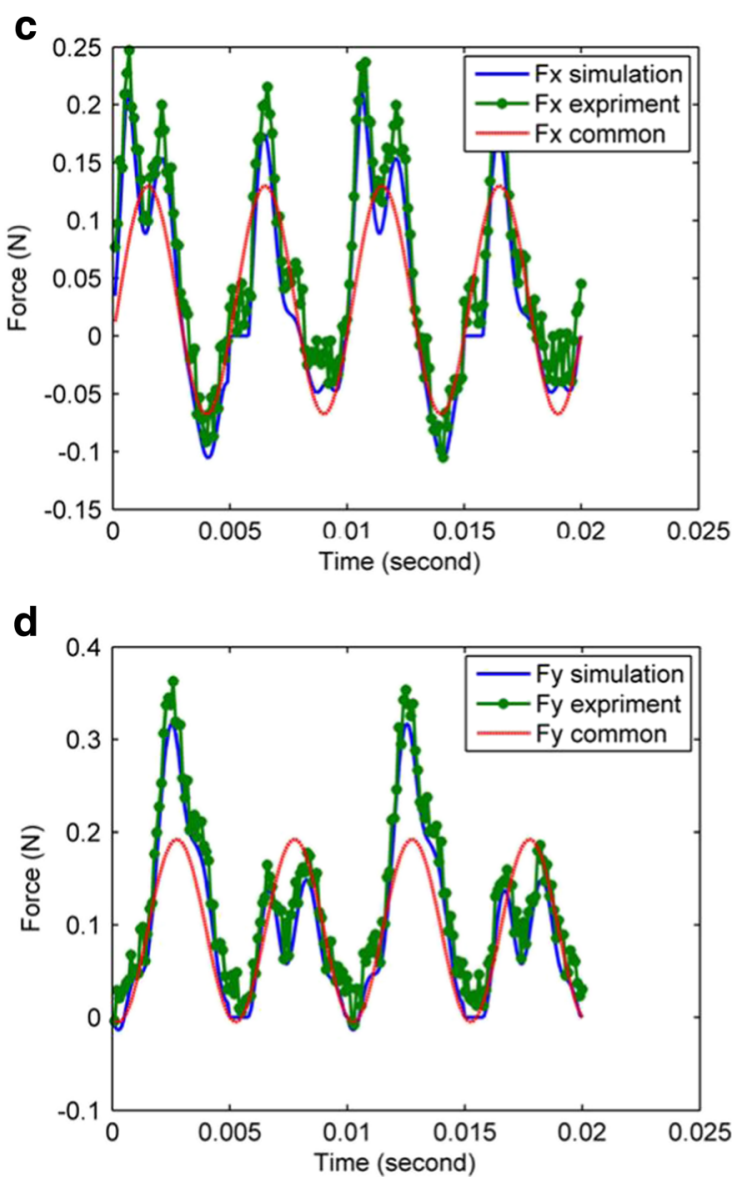

Fig. 10 One-millimetre cutter with 5- $\mu \mathrm{m}$ feed per tooth. a Trajectories of the cutter. b Instantaneous chip thickness. c Cutting force in $x$ direction. d Cutting force in $y$ direction. 
In the last set of the experiments, the 1-mm diameter cutter with $1-\mu \mathrm{m}$ feed per tooth was used. Figure 11a shows the trajectories of the cutter; it can be found that there are several intersection points between the current and the previous cutting trajectories due to tool runout and the machining system vibration. As a result of this phenomenon, the uncut chip thickness in a tooth cutting trajectory is discontinuous as shown in Fig. 11b. The uncut chip thickness drops to 0 several times (circled in Fig. 11b), which means that the tool and workpiece separate in these time intervals and no material is removed, while in the conventional uncut chip thickness model, as shown in the dot dash line, the uncut chip thickness is continuous in a tooth cutting trajectory. The cutting forces in the $x$ and $y$ directions obtained by the proposed method, the conventional method and the experiments are shown in Fig. 11c, d. From the simulation results obtained by the proposed method, it can be noted that the first tooth cut more material than the second tooth, which is caused by the tool runout, and the cutting forces drop to 0 when the material in the current tool trajectory has been already removed by the previous cutting trajectories. The cutting force profile predicted by the conventional method is a continuous sine wave. Same as the second experiment, the experimental results show that cutting forces fluctuate several times in 1 revolution, and the maximum cutting forces in the $x$ and $y$ directions are significantly larger than those predicted from the conventional method. The proposed model can realize tool runout and machining dynamics, capture the transient separation of tool-workpiece phenomenon and hence provide more accurate cutting force prediction (Fig. 11c, d).

In order to further verify the effectiveness of the proposed model, the cutting force components have been analysed in the frequency domain via a FFT analysis. Figure 12 shows the FFT analysis of the cutting force in the $x$ and $y$ directions obtained by conventional method, proposed method and the experiment, respectively. It can be found that in the frequency domain, the conventional method can only capture the tooth passing frequency which is twice the spindle rotational frequency while the proposed method can capture the runout frequency, tooth passing frequency and dynamic frequencies, which is in good agreement with the experimental results. It is also
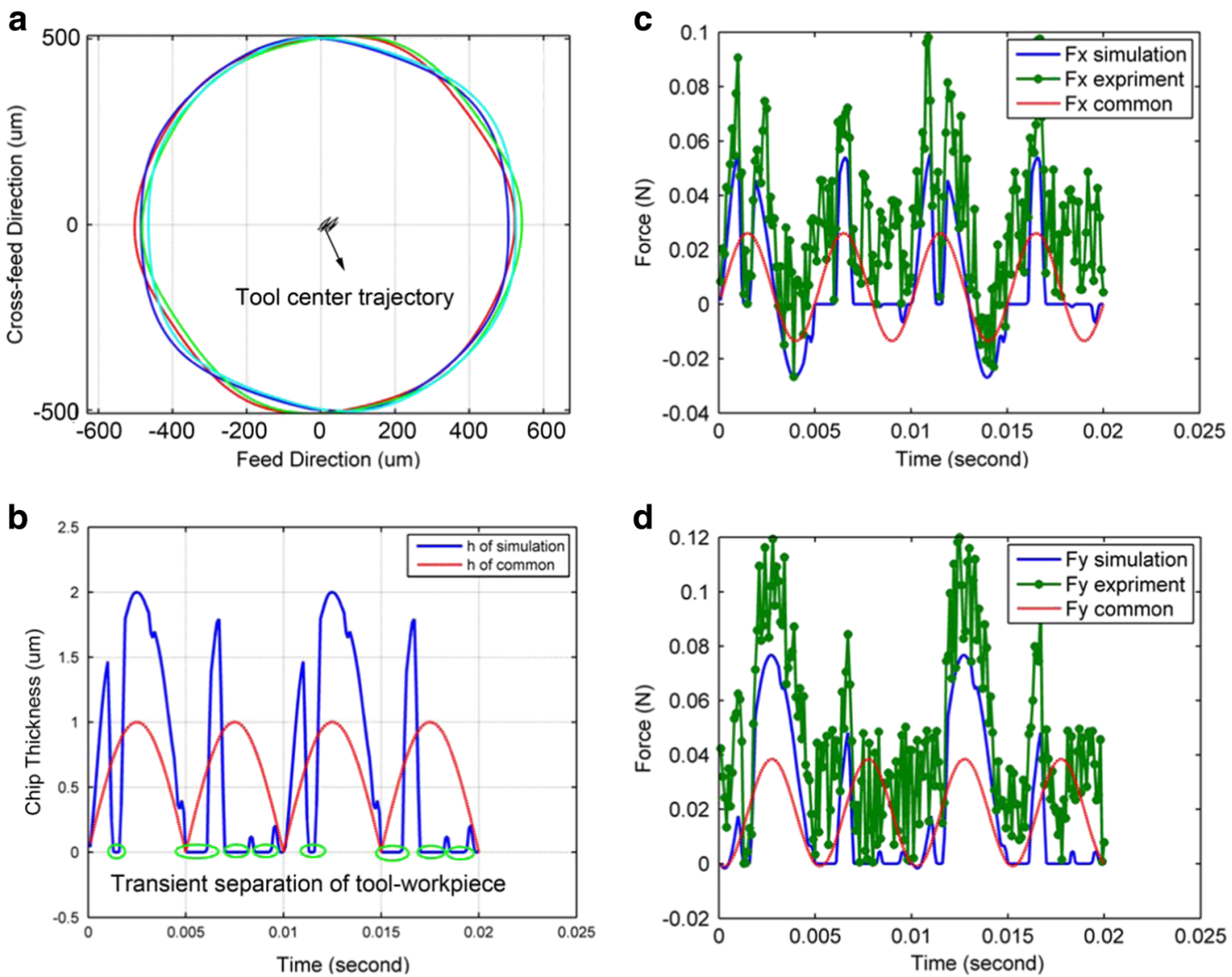

Fig. 11 One-millimetre cutter with 1- $\mu \mathrm{m}$ feed per tooth. a Trajectories of the cutter. b Instantaneous cutting thickness. $\mathbf{c}$ Cutting forces in $x$ direction. $\mathbf{d}$ Cutting forces in $y$ direction. 

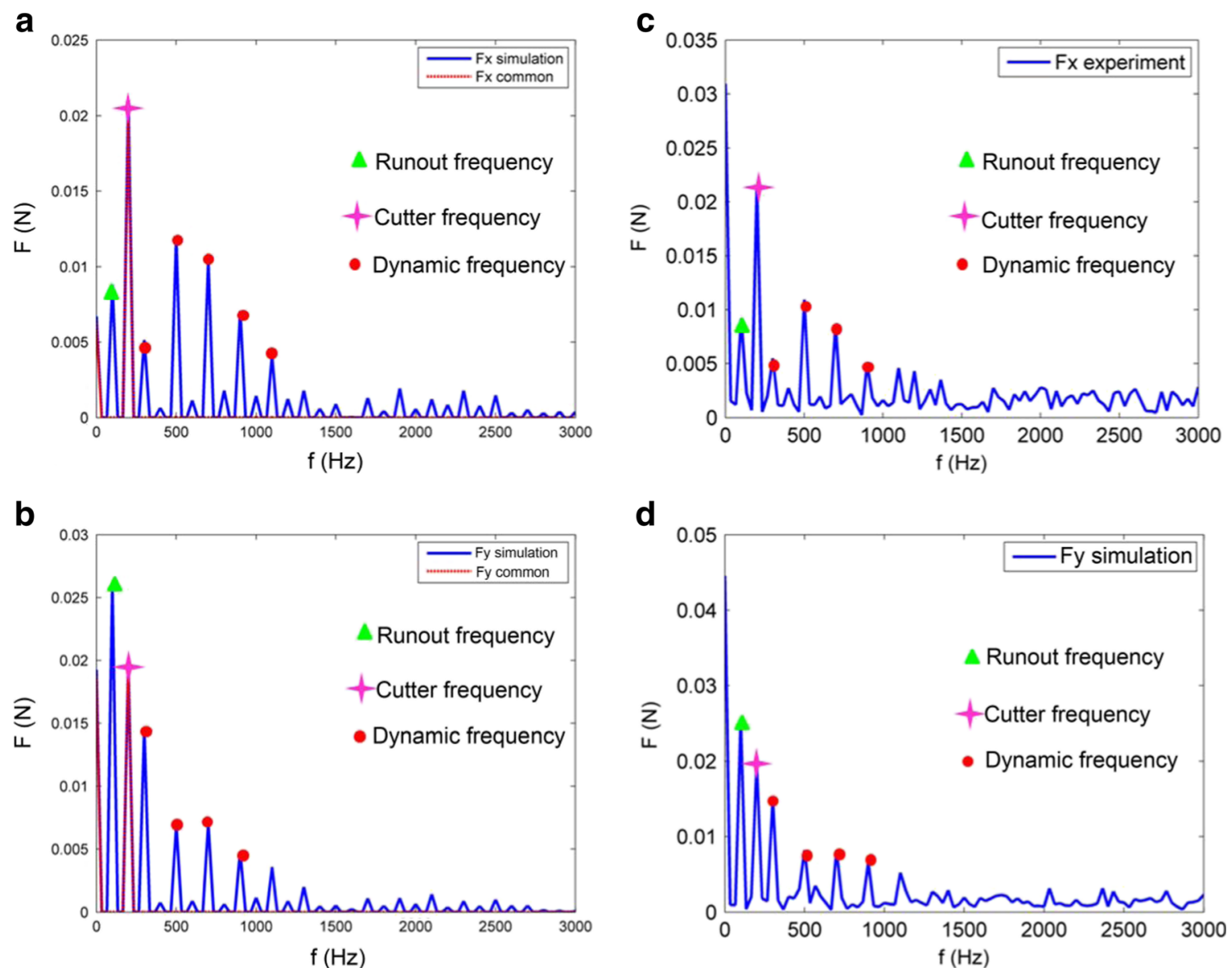

Fig. 12 FFT analysis of cutting forces for $0.1-\mathrm{mm}$ cutter with $1-\mu \mathrm{m}$ feed per tooth. a FFT analysis in $x$ direction of simulation results. b FFT analysis in $x$ direction of experiment results. $\mathbf{c}$ FFT analysis in $y$ direction of simulation results. d FFT analysis in $y$ direction of experiment results

noted that in the $y$ direction, the runout plays a more dominant role in the cutting force, which means that the runout value is larger than the feed per tooth in this direction.

Table 2 summarizes the results of using the 1-mm tool with $1-\mu \mathrm{m}$ feed per tooth from the conventional method, proposed method and the experiment. It should be noted that for the $1-\mu \mathrm{m}$ feed per tooth, the cutting forces are difficult to predict due to the irregular changing of the instantaneous cutting thickness, and the predicted values show relatively large errors. However, the proposed method provides less errors compared with the conventional method, i.e. reducing the cutting force prediction errors from approx. 70 to $35 \%$. In addition, the proposed method provides excellent results in the frequency domain prediction.
Table 2 Result comparison of 1$\mathrm{mm}$ cutter with $1-\mu \mathrm{m}$ feed per tooth

\begin{tabular}{|c|c|c|c|c|c|}
\hline \multirow[t]{2}{*}{$1-\mu \mathrm{m}$ feed per tooth } & \multicolumn{2}{|c|}{ Maximum force $(\mathrm{N})$} & \multicolumn{3}{|c|}{ Dominate frequency $(\mathrm{Hz})$} \\
\hline & Direction & $\begin{array}{l}\text { Error } \\
(\%)\end{array}$ & Runout & $\begin{array}{l}\text { Tooth } \\
\text { passing } \\
\text { frequency }\end{array}$ & Dynamic frequency \\
\hline \multirow[t]{2}{*}{ Experiment } & $X: 0.09$ & - & \multirow[t]{2}{*}{100} & \multirow[t]{2}{*}{200} & $305 ; 500 ; 710 ; 908$ \\
\hline & $Y: 0.12$ & - & & & $300 ; 500 ; 700 ; 900$ \\
\hline \multirow{2}{*}{$\begin{array}{l}\text { Proposed simulation } \\
\text { method }\end{array}$} & $X: 0.058$ & 36 & \multirow[t]{2}{*}{100} & \multirow[t]{2}{*}{200} & $305 ; 500 ; 710 ; 908 ; 1100$ \\
\hline & $Y: 0.078$ & 35 & & & $300 ; 500 ; 700 ; 900$ \\
\hline \multirow[t]{2}{*}{ Conventional simulation method } & $X: 0.022$ & 76 & \multirow[t]{2}{*}{ N/A } & \multirow[t]{2}{*}{200} & \multirow[t]{2}{*}{$\mathrm{N} / \mathrm{A}$} \\
\hline & $Y: 0.039$ & 68 & & & \\
\hline
\end{tabular}




\section{Conclusions}

In this paper, an improved uncut chip thickness model has been developed by considering tool runout and the machine tool system vibration. A numerical iterative algorithm based on accurate calculation of the wavy form surface contour left by all previous cutting trajectories and its interaction with the current cutting trajectory is established to determine instantaneous uncut chip thickness. A precise cutting force model has been formulated based on the proposed uncut chip thickness model. Simulations using the proposed model and conventional model were carried out using three levels of feed per tooth (1, 5 and $25 \mu \mathrm{m} /$ tooth), and the results were compared with micro milling experiments. The following conclusions can be drawn:

- The tool runout and machine tool vibration result in the fluctuation of the dynamic cutting forces which were observed by the simulation using the proposed model and the micro milling experiments.

- Transient separation of tool-workpiece in one tooth passing period at a small feed rate ( 1 and $5 \mu \mathrm{m} /$ tooth) was observed in the simulation using the proposed model, and this phenomenon results in more fluctuations of the dynamic cutting forces as validated by the experiments.

- The proposed cutting force model has been verified by the micro milling experiments over a wide range of feed rate, and the results show that the proposed model provides more accurate cutting force prediction than the conventional model in terms of the magnitude and frequency components, particularly at a small feed per tooth.

Acknowledgements The authors gratefully acknowledge the financial support of the Engineering and Physical Sciences Research Council (EP/ M020657/1), National Natural Science Foundation of China (Grant No. 51505107) and the project (HIT.NSRIF.2017029) supported by the Natural Scientific Research Innovation Foundation in Harbin Institute of Technology.

\section{Compliance with ethical standards}

Conflict of interest The authors declare that they have no conflict of interest.

Open Access This article is distributed under the terms of the Creative Commons Attribution 4.0 International License (http://creativecommons. org/licenses/by/4.0/), which permits unrestricted use, distribution, and reproduction in any medium, provided you give appropriate credit to the original author(s) and the source, provide a link to the Creative Commons license, and indicate if changes were made.

\section{References}

1. Cheng K, Huo D (2013) Micro cutting: fundamentals and applications. Wiley, Chichester
2. Liu X, DeVor RE, Kapoor SG, Ehmann KF (2004) The mechanics of machining at the microscale: assessment of the current state of the science. J Manuf Sci Eng 126:666-678

3. Huo D, Choong Z, Shi Y, Hedley J, Zhao Y (2016) Diamond micromilling of lithium niobate for sensing applications. J Micromech Microeng 26:095005

4. Huo D, Cheng K (2010) Experimental investigation on micromilling of oxygen-free, high-conductivity copper using tungsten carbide, chemistry vapour deposition, and single-crystal diamond micro tools. Proc Inst Mech Eng B J Eng Manuf 224:9951003

5. Huo D, Lin C, Dalgarno K (2014) An experimental investigation on micro machining of fine-grained graphite. Int J Adv Manuf Technol 2014(72):943-953

6. Huo D, Lin C, Choong Z, Pancholi K, Degenaar P (2015) Surface and subsurface characterisation in micro milling of monocrystalline silicon. Int J Adv Manuf Technol 81:1319-1331

7. Lai X, Li H, Li C et al (2008) Modelling and analysis of micro scale milling considering size effect, micro cutter edge radius and minimum chip thickness. Int J Mach Tools Manuf 48(1):1-14

8. Li H, Lai X, Li C et al (2007) Modelling and experimental analysis of the effects of tool wear, minimum chip thickness and micro tool geometry on the surface roughness in micro-end-milling. J Micromech Microeng 18(2):025006

9. Bao WY, Tansel IN (2000) Modeling micro-end-milling operations. Part II: tool run-out. Int J Mach Tool Manuf 40:2175-2192

10. Bao WY, Tansel IN (2000) Modeling micro-end-milling operations. Part I: analytical cutting force model. Int J Mach Tool Manuf 40: 2155-2173

11. Li C, Lai X, Li H et al (2007) Modeling of three-dimensional cutting forces in micro-end-milling. J Micromech Microeng 17(4):671

12. Kang IS, Kim JS, Seo YW (2008) Cutting force model considering tool edge geometry for micro end milling process. J Mech Sci Technol 22(2):293-299

13. Gye HR, Song BU, Lim YS et al (2013) Prediction of cutting force and tool deflection in micro flat end milling. Int $\mathrm{J}$ Mater Mech Manuf 1(1):13-16

14. Wang S, Chen D, Jang M et al (2012) Development of micromilling force model and cutting parameter optimization. Trans Nonferrous Metals Soc China 22:851-858

15. Lee HU, Cho DW, Ehmann KF (2008) A mechanistic model of cutting forces in micro-end-milling with cutting-conditionindependent cutting force coefficients. J Manuf Sci Eng 130(3): 031102

16. Vogler MP, DeVor RE, Kapoor SG (2003) Microstructure-level force prediction model for micro-milling of multi-phase materials. J Manuf Sci Eng 125(2):202-209

17. Jin X, Altintas Y (2011) Slip-line field model of micro-cutting process with round tool edge effect. J Mater Process Technol 211(3):339-355

18. Kumanchik LM, Schmitz TL (2007) Improved analytical chip thickness model for milling. Precis Eng 31(3):317-324

19. Schmitz TL, Couey J, Marshb E, Mauntler N, Hughes D (2006) Run-out effects in milling: surface finish, surface location error, and stability. Int J Mach Tools Manuf 47(5):841-851

20. Li K, Zhu K, Mei T (2016) A generic instantaneous undeformed chip thickness model for the cutting force modeling in micro-milling. Int J Mach Tools Manuf 105:23-31

21. Zhang X, Ehmann KF, Yu T et al (2016) Cutting forces in microend-milling processes. Int J Mach Tools Manuf 107:21-40

22. Malekian M, Park SS, Jun MBG (2009) Modeling of dynamic micro-milling cutting forces. Int $\mathrm{J}$ Mach Tool Manuf 49:586-598 